\title{
KEPEMIMPINAN ORGANISASI MASA DEPAN KONSEP DAN STRATEGI KEEFEKTIFAN*)
}

\author{
Nursya'bani Purnama \\ Fakultas Ekonomi \\ Universitas Islam Indonesia
}

\begin{abstract}
Future organization will face business environment changes that demand organization to build new competence. Leadership becomes a critical factor that must be possessed by future organization leaders. To sustain organization's success, future organization leaders have to formulate the precise and clear vision and communicate the vision through all organization elements. The prominent competence possessed by future organization leaders involves strategic thinking ability, leadership in change and skill developing a good relationship.

In addition to there are special skills concering difficult learning, maximing energy, resonant simplicity, multiple focus, and mastering inner sense.
\end{abstract}

Key words: Kepemimpinan, Kompetensi, Strategi Keefektifan

\section{PENDAHULUAN}

Tanpa memperhatikan industri, ukuran atau lokasi, memasuki abad 21, organisasi bisnis dihadapkan pada berbagai tantangan bisnis yang kritis dan secara kolektif tantangan-tantangan tersebut menuntut organisasi membangun kemampuan baru. Tantangan yang paling kompetitif adalah penyesuaian kepada perubahan yang tiada henti-hentinya. Faktor-faktor lingkungan bisnis yang terus mengalami perubahan, menjadikan masa depan bisnis semakin tidak pasti dan mengalami turbulansi. Perubahan-perubahan yang terjadi menuntut organisasi untuk membangun kemampuan baru. Organisasi harus selalu dalam kondisi transformasi yang tidak pernah berakhir, bersifat fundamental, dan kontinyu.

Mendasarkan pada gambaran di atas, kepemimpinan yang efektif menjadi faktor kritis yang sangat menentukan keberhasilan organisasi. Untuk mengantisipasi perubahan-perubahan yang terjadi, organisasi membutuhkan pemimpin dan kepemimpinan yang cocok dengan karakteristik organisasi masa depan. Pertanyaannya, kepemimpinan yang bagaimana yang harus dimiliki yang bisa membawa organisasi mencapai tujuannya? Untuk menjawab hal itu, tulisan ini akan mencoba mencari dan menelusuri

*) Pernah diterbitkan pada Jurnal Siasat Bisnis edisi No. 5 Vol. 1, 2000 
jawaban, serta menyodorkan karakteristik kepemimpinan yang efektif organisasi masa depan. Pembahasan berturut-turut meliputi teori kepemimpinan, karakteristik kepemimpinan yang efektif, pendekatan peningkatan keefektifan kepemimpinan, dan disertai model diagnosis perilaku organisasi yang mendukung kepemimpinan yang efektif.

\section{TEORI KEPEMIMPINAN}

\section{Teori Kepemimpinan}

Beberapa teori kepemimpinan telah dikemukakan oleh para ahli. Menurut Robbin (1996) terdapat tiga pendekatan teori kepemimpinan, yaitu: 1) pendekatan teori sifat, 2) pendekatan teori perilaku, dan 3) pendekatan teori kontinjensi. Menurut teori sifat, pemimpin itu dilahirkan, bukan dibuat. Para pemimpin memiliki pembawaan sejak lahir yang memungkinkan mereka memimpin orang lain. Teori perilaku menyatakan bahwa isu utama dalam kepemimpinan adalah menjadikan pemimpin efektif atau gaya kepemimpinan terbaik. Keefektifan pemimpin menggunakan gaya khusus untuk memimpin perorangan dan kelompok dalam mencapai tujuan tertentu akan menghaisilkan moral dan produktivitas yang tinggi. Sedangkan teori kontinjensi menyatakan bahwa keefektifan personalitas, gaya, atau perilaku pemimpin tergantung pada sejauhmana pemimpin mampu menyesuaikan dengan situasi yang dihadapi. Beberapa pendekatan yang lebih mutakhir antara lain teori kepemimpinan karismatik (Housse: 1977, Conger dan Kanungo:1988), kepemimpinan transaksional-transformasional (Burn: 1978, Bass: 1985, Seltzer dan Bass: 1990, Bass dan Avolio: 1993), dan kepemimpinan visioner (Nanus:1992).

Menjadi pemimpin tidak bisa terjadi seketika, tetapi membutuhkan perjalanan yang tidak singkat. Bennis dalam Hitt (1993), memberikan pandangan secara umum tentang kepemimpinan. Dia mengatakan bahwa proses menjadi pemimpin identik dengan proses menjadi manusia seutuhnya. Jalur yang harus ditempuh pemimpin sebagai orang yang berfungsi sepenuhnya melalui sejumlah kebijaksanaan berikut:

1) Kepemimpinan pada umumnya didefinisikan sebagai suatu pengaruh, seni atau proses mempengaruhi orang sehingga mereka akan bertindak secara sukarela menuju pencapaian tujuan kelompok.

2) Pengaruh ini ditimbulkan melalui hubungan pribadi yang efektif antara pemimpin dan pengikut. Hubungan ini akan mendongkrak pengikut menjadi pribadi yang lebih baik. 
3) Bagi seorang pemimpin agar dapat menyelaraskan pengikut menjadi pribadi yang lebih baik, pemimpin harus berada pada "level keadaan yang lebih baik" dari pengikutnya.

4) Dengan level kedaan yang lebih baik berarti pemimpin memiliki kematangan secara psikologis. Derajat kemampuan pemimpin menciptakan hubungan yang mendorong pertumbuhan pengikut sebagai pribadi yang terpisah merupakan ukuran pertumbuhan psikologis.

5) Pemimpin yang matang kepribadiannya adalah orang yang berfungsi sepenuhnya. Orang yang berfungsi sepenuhnya adalah orang yang menggunakan semua kemampuan yang telah dibentuk menjadi suatu kesatuan.

Untuk menjadi orang yang berfungsi sepenuhnya, menurut paradigma kepemimpinan, setiap manusia memiliki potensi untuk mendaki empat tingkatan potensi manusia, yaitu:

1) Empirical existence (eksistensi empiris) Hidup dalam dunia sehari-hari, mencari kesenangan dan menghindari kesedihan. Pada tingkatan ini seseorang akan mampu menciptakan peta untuk mengatasi persoalan kehidupan sehari-hari.

2) Consciousness at large (kesadaran yang luas)

Memperoleh pengetahuan obyektif, pengetahuan yang valid dan universal. Pada tingkatan ini seseorang bisa menciptakan peta pengetahuan obyektif, valid, dan universal.

3) Spirit (semangat)

Mengidentifikasi gagasan-gagasan yang menonjol dalam gerakangerakan, partai politik, lembaga-lembaga atau organisasi. Pada tingkatan ini seseorang akan mampu menciptakan peta untuk memandu mengidentifikasi gagasan dan keyakinan.

4) Existenz (eksistensi)

Menemukan jatidiri secara otentik. Pada tingkatan ini seseorang akan sadar bahwa dia memiliki kebebasan untuk menciptakan peta diri sendiri.

\section{Kompetensi Kepemimpinan}

Untuk menjadi pemimpin atau disebut menjadi orang yang berfungsi sepenuhnya, seorang pemimpin harus melewati 4 tingkatan seperti disinggung di atas (eksistensi empiris, kesadaran yang luas, semangat, dan eksistensi). Tingkatan tersebut bersifat hirarkis, setiap tingkatan yang lebih tinggi mencakup dan memberi arahan tingkatan-tingkatan sebelumnya. Pemimpin yang efektif akan selalu berusaha mengembangkan diri dan 
bergerak mendaki tangga hirarki. Pemimpin tidak punya batas untuk mendaki puncak.

Untuk mendaki tingkatan-tingkatan dalam tangga potensi manusia, seorang pemimpin harus memiliki kompetensi. Kompetensi adalah karakter mendasar yang harus dimiliki seseorang yang menyebabkan dia sanggup menunjukkan kinerja yang efektif atau superior di dalam suatu pekerjaan, atau karakter mendasar yang memberikan kontribusi terhadap kinerja menonjol dalam suatu pekerjaan (Spencer dan Spencer: 1993). Menurut Hitt (1993) terdapat 25 kompetensi penting yang harus dimiliki seorang pemimpin yang terangkum dalam 5 dimensi, yaitu: reason, sources of power, knowledge, core leadership functions, dan character (lihat Tabel 1.)

Tabel 1. Leadership Competences

\begin{tabular}{|c|c|}
\hline Dimensions of Leadership & Leadership Competences \\
\hline Reason & $\begin{array}{ll} & \text { Conceptual skills } \\
\square & \text { Logical thinking } \\
\square & \text { Creative thinking } \\
\square & \text { Holistic thinking } \\
\square & \text { Communication } \\
\end{array}$ \\
\hline Sources of power & $\begin{array}{ll}\square & \text { Staff } \\
\square & \text { Information } \\
\square & \text { Networks } \\
\end{array}$ \\
\hline Knowledge & $\begin{array}{ll}\square & \text { Knowing oneself } \\
\square & \text { Knowing the job } \\
\square & \text { Knowing the organization } \\
\square & \text { Knowing thw business is in } \\
\square & \text { Knowing thw world } \\
\end{array}$ \\
\hline Core leadership functions & $\begin{array}{ll}\square & \text { Valuing } \\
\square & \text { Visioning } \\
\square & \text { Coaching } \\
\square & \text { Empowering } \\
\square & \text { Team building } \\
\square & \text { Promoting quality }\end{array}$ \\
\hline Character & $\begin{array}{ll}\square & \text { Identity } \\
\square & \text { Independence } \\
\square & \text { Authenticity } \\
\square & \text { Responsibility } \\
\square & \text { Courage } \\
\square & \text { Integrity }\end{array}$ \\
\hline
\end{tabular}

Sumber: Hitt, William D. (1993),"The Model Leader: A Fully Functioning Person", Leadership \& Development Journal, Vol.14, No.7, pp. 4-11. 
1) Reason (Nalar)

Setiap pemikiran manusia dipenuhi oleh konsep dan fakta. Nalar bisa mengkonsolidasikan fakta dan konsep yang berlainan menjadi satu kesatuan yang bermakna. Nalar selalu mempertanyakan, menguji, dan menjawab fakta. Nalar menghubungkan semua orang dan memungkingkan berhubungan dengan orang lain dengan berbagai budaya, bahasa, yang mungkin bertentangan. Perwujudan nalar meliputi: 1) ketrampilan konseptual, yaitu kemampuan untuk melakukan abstraksi dan generalisasi, 2) pemikiran logis, yaitu kemampuan menerapkan pendekatan sistematis dalam pemecahan masalah, 3) pemikiran kreatif, yaitu kemampuan untuk membawa gagasan menjadi kenyataan, 4) pemikiran holistik, yaitu kemampuan mengangkat situasi total, dan 5) komunikasi, yaitu kemampuan berdialog dengan orang lain, beradu nalar dengan orang lain untuk mencari kebenaran yang bisa diterima dua pihak.

2) Sources of power (sumber kekuasaan)

Saat ini kekuasaan dianggap sesuatu yang penting dalam kepemimpinan yang efektif. Pemimpin yang efektif harus memiliki sumber-sumber kekuasaan yang utama, yaitu: 1) staf, yaitu tim yang terdiri orang-orang yang punya kesiapan, bersedia bekerja, dan memiliki kemampuan melaksanakan pekerjaan, 2) informasi, yaitu pengetahuan yang dibutuhkan untuk melakukan pekerjaan, dan 3) jaringan, yaitu kontak pribadi, dengan siapa gagasan, informasi maupun sumber daya bisa dibagi.

Handy (1996) menyebutkan tiga atribut yang perlu dimiliki oleh pemimpin agar ia memperoleh kekuasaan dari pengikutnya, yaitu: memiliki keyakinan diri yang kuat yang diimbangi dengan mempertanyakan kembali keyakinan tersebut, memiliki kegairahan terhadap pekerjaan yang diimbangi dengan kesadaran terhadap dunia lain, dan mencintai orang yang diimbangi dengan keberanian untuk berjalan dalam kesendirian. Pemimpin juga harus mendapat kredibilitas dan kepercayaan dari para bawahan (Chandra: 1997; Pradiansyah: 1997). Agar memperoleh kredibilitas, seorang pemimpin harus jujur, melihat jauh ke depan, memberi inspirasi, dan cakap.

3) Knowledge (pengetahuan)

Pemimpin yang efektif harus memiliki pengetahuan. Meskipun tidak semua informasi bisa dikuasai, mereka harus bisa menyaring informasi yang penting. Pemimpin yang efektif memiliki 5 karakteristik pengetahuan, meliputi: 1) mengetahui diri sendiri mengetahui kekuatan 
dan kelemahan diri sendiri dan secara aktif mencari umpan balik untuk pertumbuhan, 2) mengetahui pekerjaan -memahami persyaratan kerja dan bagaimana pekerjaan memberi kontribusi pada organisasi, 3) mengetahui organisasi -memahami budaya organisasi dan bagaimana melakukan segala sesuatu secara efektif dan efisien, 4) mengetahui bisnis yang dimasuki- memahami lingkungan eksternal dengan baik untuk mengetahui kebutuhan klien dan apa yang bernilai bagi klien, dan 5) mengetahui dunia -memahami komunitas dunia dan bagaimana komunitas yang kecil berhubungan dengan yang besar.

4) Core leadership function (fungsi kepemimpinan inti) Pemimpin yang efektif harus mampu mengangkat nilai-nilai pengikutnya dengan terus mendorong para pengikut untuk mendaki hirarki sehingga muncul "nilai baru". Pemimpin yang efektif melaksanakan 6 fungsi inti, yaitu: 1) menilai -mengetahui nilai-nilai organisasi dan mampu menterjemahkan nilai-nilai tersebut dalam praktek, 2) membuat -memiliki gambaran mental yang jelas tentang masa depan yang dikehendaki organisasi, 3) memandu -membantu orang lain mengembangkan pengetahuan dan ketrampilan yang dibutuhkan untuk mencapai visi tersebut, 4) memberdayakan -membantu orang lain bergerak mencapai misi tersebut, 5) membangun tim -membangun koalisi dengan orang yang membangun komitmen pada diri mereka sendiri untuk mencapai visi tersebut, dan 6) mempromosikan kualitas -mencapai reputasi untuk selalu memenuhi atau melebihi harapan pelanggan.

5) Character (karakter)

Pemimpin yang baik harus memiliki 6 karakteristik berikut: 1) identitas mengetahui dia siapa dan dia bukan siapa, memiliki keutuhan dan integrasi, 2) kemandirian -menjadi orang yang bisa mengarahkan dirinya sendiri, 3) keaslian -menunjukkan jati diri yang sesungguhnya pada orang lain, mempertahankan kesesuaian antara nilai diri sendiri dengan nilai yang ada di luarnya, 4) tanggung jawab terhadap tindakan dan keputusan yang dilakukan, 5) keberanian untuk terus melangkah meskipun ada hambatan, dan 6) integritas -dipandu oleh sejumlah prinsip-prinsip moral dan diakui oleh orang lain sebagai orang yang berintegritas.

Di samping harus memiliki kompetensi di atas, pemimpin yang efektif bagi organisasi masa depan juga harus memiliki sejumlah ketrampilan khusus. White, et al. (1997) menyebutkan ketrampilan khusus yang harus dimiliki meliputi: difficult learning, maximizing energy, resonant simplicity, multiple focus, dan mastering inner sense. 


\section{Difficult learning}

Dalam organisasi belajar, pemimpin organisasi harus mampu mendorong seluruh anggota organisasi untuk mengidentifikasi apa yang belum mereka ketahui dan segala sesuatu permasalahan yang belum ditemukan cara pemecahannya.

\section{Maximing energy}

Pemimpin organisasi masa depan dengan memaksimalkan daya harus bisa membuat keputusan bisnis yang berkualitas, memiliki dorongan yang kuat untuk keluar dari status quo masa kini atau dari suatu pemecahan yang kompromistis.

\section{Resonant simplicity}

Pemimpin organisasi masa depan harus punya ketrampilan berpikir dan berlogika secara sederhana untuk mendukung kelancaran proses komunikasi.

\section{Multiple focuses}

Pemimpin organisasi masa depan harus bisa menyatukan fokus cara berpikir dan bertindak anggota organisasi yang berbeda menyangkut rencana strategis dan kegiatan, melalui metode persuasif dan advocacy.

\section{Mastering inner sense}

Dalam kondisi yang diwarnai berbagai perubahan, keputusan yang harus dibuat cepat pemimpin organisasi masa depan di samping harus mampu berlogika dan menggunakan rasio, juga dituntut memiliki kemampuan inner sense (kemampuan ilmu dalam). Dalam kondisi yang serba gampang berubah dengan cepat, dengan kemampuan ilmu dalam diharapkan seorang pemimpin dapat membuat keputusan dengan cepat meskipun dengan resiko harus keluar dari "rel" aturan birokrasi.

\section{KEPEMIMPINAN ORGANISASI MASA DEPAN}

\section{Visi dan Kompetensi Kepemimpinan Organisasi Masa Depan}

Dengan landasan penalaran yang tajam, Brill dan Worth (1997) memberikan ramalan bahwa organisasi masa depan yang akan mampu bersaing harus memiliki visi yang jelas dan terarah. Visi adalah suatu pernyataan yang berisi arahan yang jelas tentang apa yang harus diperbuat organisasi di masa yang akan datang. "A vision is a realistic, credible, attractive future for your organization" (Nanus: 1992). Visi yang jelas dan 
tepat sesuai dengan kebutuhan organisasi akan mampu menumbuhkan hal-hal berikut: 1) menumbuhkan komitmen karyawan terhadap pekerjaan dan mampu memupuk semangat kerja karyawan, 2) menumbuhkan rasa kebermaknaan di dalam kehidupan kerja karyawan, 3) menumbuhkan standar kerja yang prima, 4) menjembatani keadaan organisasi masa sekarang dan masa depan. Penelitian Collin dan Porras (dalam Pradiansyah: 1997), menunjukkan bahwa organisasi yang memiliki visi dapat melampaui prestasi organisasi yang tidak memiliki visi sampai 55 kali.

Suatu survai yang dilaksanakan majalah Fortune terhadap 1500 pimpinan senior perusahaan, mengungkapkan ciri-ciri atau kemampuan paling dominan yang harus dimiliki pimpinan pada tahun 2000 adalah kemampuan merumuskan visi masa depan (Korn: 1989 dalam Chandra: 1997). Menurut Kotter (1996) visi organisasi merupakan tanggung jawab pemimpin organisasi. Visi adalah komponen sentral dari kepemimpinan yang hebat (great leadership). Dengan visinya seorang pemimpin memberikan jaminan kepastian/keamanan kepada anak buahnya dalam menyesuaikan diri dengan perubahan karena pengaruh perubahan lingkungan (Pradiansyah: 1997).

Sudah jelas bahwa pekerjaan yang tidak ringan dan menjadi keharusan bagi seorang pemimpin untuk dapat merumuskan visi kepemimpinannya (visi organisasi) dengan jelas dan terarah. Untuk dapat merumuskan visi yang jelas, kepemimpinan organisasi harus mempertanyakan hal-hal berikut (Nanus: 1992): apa visi dan tujuan organisasi saat ini, apa manfaat organisasi bagi masyarakat, apa ciri wilayah kerja dan kerangka kerja institusional dimana organisasi beroperasi, apa keunikan organisasi di dalam wilayah garapan atau di dalam struktur yang dimasuki, dan hal-hal apa yang harus dilakukan agar organisasi maju dan berkembang?

Di depan telah disodorkan kompetensi yang harus dimiliki seorang pemimpin yang terangkum dalam 5 dimensi. Mendasarkan pada fenomena perubahan yang terus menerus terjadi, di samping harus memiliki visi yang jelas dan terarah, pemimpin organisasi masa depan harus memiliki kompetensi yang menonjol sesuai lingkungan perubahan. Spencer, et al. (1994) mengidentifikasi beberapa kompetensi yang akan semakin penting bagi pemimpin organisasi masa depan yang meliputi: 1) kemampuan berpikir strategis, yaitu kemampuan untuk memahami kecenderungan perubahan lingkungan yang berlangsung cepat, peluang pasar, ancaman kompetisi, kekuatan dan kelemahan organisasi yang dipimpinnya, serta mampu mengidentifikasi tanggapan-tanggapan strategis, 2) kepemimpinan dalam perubahan, yaitu kemampuan untuk mengkomunikasikan visi 
strategis organisasi kepada seluruh pihak yang terkait, menciptakan komitmen dan motivasi, penggerak inovasi dan semangat kewirausahaan, serta mampu mengalokasikan sumber daya organisasi secara optimal untuk mengantisipasi perubahan yang akan terjadi, 3) pengelolaan hubungan, yaitu kemampuan untuk membina hubungan di tengah-tengah jaringan kerja yang kompleks, baik dengan partner usaha maupun pihak lain yang memiliki pengaruh terhadap keberlangsungan organisasi.

\section{Karakteristik Pemimpin yang Efektif}

Diyakini banyak pihak bahwa organisasi masa depan menghadapi perubahan-perubahan yang akan mempengaruhi kehidupan organisasi. Apapun gaya kepemimpinan yang akan dipilih, dalam kondisi seperti itu organisasi membutuhkan kepemimpinan yang efektif sehingga bisa mengantar organisasi mencapai tujuannya. Pada Tabel 2 disajkan berbagai ide/gagasan dari sejumlah tokoh mengenai kepemimpinan yang efektif.

Tabel 2. Notions of Effective Leadership

\begin{tabular}{|l|l|}
\hline Plato & $\begin{array}{l}\text { Effective leaders are philoshoper-king } \\
\text { Effective leaders are power-wielders, individuals who employ manipulation, } \\
\text { exploitation, and deviousness to achieve their own ends. } \\
\text { Effective leaders have charisma-that special spiritual power pr personal quality } \\
\text { that gives an individual influence over large numbers of people. } \\
\text { Effective leaders view management as a science. } \\
\text { Effective leaders view management as a art. } \\
\text { DePree } \\
\text { Drucker }\end{array}$ \\
$\begin{array}{l}\text { Effective leaders are able to carry out the functions of management:planning, } \\
\text { organizing, directing, and measuring. } \\
\text { Effective leaders have mastered the art of getting things done througth others. } \\
\text { Effective leaders understand the human side of enterprise. }\end{array}$ \\
$\begin{array}{l}\text { Likert } \\
\text { Blake and Mouton } \\
\text { lacocca } \\
\text { Bradford and Cohen } \\
\text { Block }\end{array}$ & $\begin{array}{l}\text { Effective leaders choose a leadership style that reflects a concern for both } \\
\text { production and people. } \\
\text { Kanter } \\
\text { Effective leaders focus on the three "Ps", people, product, and profit-in that } \\
\text { order. } \\
\text { Effective leaders are develop people. } \\
\text { Effective leaders are empower others. } \\
\text { Effective leaders are change masters. } \\
\text { Effective leaders have vision and are able to translate the vision into action. }\end{array}$ \\
\hline
\end{tabular}




\begin{tabular}{|l|l|}
\hline Deming & $\begin{array}{l}\text { Effective leaders are able to lift followers into their better selves. } \\
\text { Effective leaders help others do quality work. }\end{array}$ \\
\hline
\end{tabular}

Sumber: Hitt, William D. (1993),"The Model of Leader: A Fully Functioning Person", Leadership \& Organizaton Development Journal, Vol. 14 No. 7.

Keefektifan kepemimpinan merupakan sesuatu yang sulit diukur karena sifatnya yang multidimesional dan kualitatif. Sebagai bahan rujukan, Tannenbaum and Schmidt (1958) dalam Sofiati (1995) menyatakan bahwa suatu studi telah dilakukan terhadap 161 manajer yang merupakan peserta Program Pendidikan Manajemen pada Sekolah Bisnis Harvard untuk mengidentifikasi karakteristik-karakteristik yang dibutuhkan untuk menjadi pemimpin yang efektif. Hasil yang diperoleh menunjukkan karakteristikkarakteristik pemimpin yang efektif meliputi: 1) mengembangkan, melatih, dan mengayomi bawahan, 2) berkomunikasi secara efektif dengan bawahan, 3) memberi informasi kepada bawahan mengenai apa yang diharapkan perusahaan dari mereka, 4) menetapkan standar hasil kerja yang tinggi, 5) mengenali bawahan beserta kemampuannya, 6) memberi peranan kepada para bawahan dalam proses pengambilan keputusan, 7) selalu memberi informasi kepada bawahan mengenai kondisi perusahaan, 8) waspada terhadap kondisi moral perusahaan dan selalu berusaha untuk meningkatkannya, 9) bersedia melakukan perubahan dalam melakukan sesuatu, dan 10) menghargai prestasi bawahan.

Jika melihat karakteristik pemimpin yang efektif tersebut, sekilas tampak bahwa keefektifan suatu kepemimpinan dapat tercapai jika seorang pemimpin mampu menjalin komunikasi yang baik dengan para bawahan, karena dipahami bahwa bersama-sama para bawahan seorang pemimpin bekerja untuk mencapai tujuan organisasi. Permasalahannya, siapa yang pantas memberikan penilaian terhadap keefektifan kepemimpinan? Seorang pemimpin adalah centre of organization, penilaian terhadap seorang pemimpin mestinya dilakukan oleh orang-orang yang ada di sekelilingnya yang selalu berinteraksi dan menjalankan aktivitas organisasi bersama-sama. Dalam hal ini, para bawahanlah yang paling mengetahui roda sebuah kepemimpinan.

\section{Tahapan Menuju Kepemimpinan yang Efektif}

Kepemimpinan adalah sebuah proses interaksi yang melibatkan pemimpin sebagai titik sentral dengan para bawahan/pengikut dan dipengaruhi oleh faktor lingkungan (situasi). Keefeketifan pemimpin sangat bergantung pada bagaimana interaksi antara pemimpin dengan bawahan 
dan situasi berlangsung. Menjadi pemimpin yang efektif, tidak bisa terjadi seketika, namun membutuhkan proses panjang. Menyadari hal itu, banyak organisasi membuat perencanaan suksesi dan pendidikan-latihan khusus untuk memperoleh figur pemimpin yang memenuhi kapabilitas sesuai persyaratan di atas. Untuk menjadi pemimpin yang efektif organisasi masa depan, menurut Quirke (1995) dalam Mulyadi (1998), 5 tahap berikut harus dilalui, yaitu: awareness (kesadaran), understanding (pemahaman), support (dukungan), involvement (keterlibatan), dan commitment (komitmen). Kesadaran akan adanya perubahan berarti seorang pemimpin memiliki kemampuan untuk menyadari, memahami, memberi dukungan, melibatkan diri, dan memiliki komitmen terhadap perubahan-perubahan yang mungkin terjadi.

\section{PENDEKATAN PENINGKATAN KEEFEKTIFAN KEPEMIMPINAN}

\section{Strategi Peningkatan Keefektifan Kepemimpinan}

Di atas telah diuraikan tentang karakteristik kepemimpinan yang efektif dan kompetensi yang harus dimiliki oleh pemimpin untuk mencapai keefektifan. Kemudian timbul pertanyaan, bagaimana seandainya sebuah kepemimpinan dinilai tidak mencapai keefektifan? Tannenbaum dan Schmidt (1958) dalam Sofiati (1995) menyebutkan bahwa untuk mengatasi kemungkinan munculnya ketidakefektifan, organisasi perlu menciptakan leadership substitutes, leadership neutralizers, dan leadership enhancers. Esensi dari ketiga strategi tersebut adalah penciptaan karakteristik tertentu pada organisasi yang menyangkut tugas dan bawahan/karyawan sebagai petunjuk dalam pelaksanaan tugas. Dengan demikian tugas seorang pemimpin dapat digantikan (leadership substitutes). Penciptaan karakteristik tertentu yang ditujukan untuk membantu tugas pemimpin dalam meningkatkan pengaruh kepada bawahan, disebut leadership enhancers. Penciptaan karakteristik tertentu yang ditujukan untuk menetralisir dan mengurangi pengaruh atasan terhadap bawahan, disebut leadership nautralizers. Operasionalisasi upaya peningkatan keefektifan kepemimpinan, organisasi dapat mengadopsi strategi yang disebut "Creative Strategies for Improving Leadership Effectiveness" (lihat tabel 3).

Tabel 3. Creative Strategies for Improving Leadership Effectiveness

\begin{tabular}{|l|l|}
\hline $\begin{array}{c}\text { Creating Substitutes for Leaders Directiveness and } \\
\text { Supportiveness }\end{array}$ & \multicolumn{2}{|c|}{$\begin{array}{c}\text { Creating Enhancers for Leaders Directiveness and } \\
\text { Supportiveness }\end{array}$} \\
\hline Develop collegial systems of guidance: & Increase subordinates perceptions of leader's influ- \\
\hline
\end{tabular}




\begin{tabular}{|c|c|}
\hline 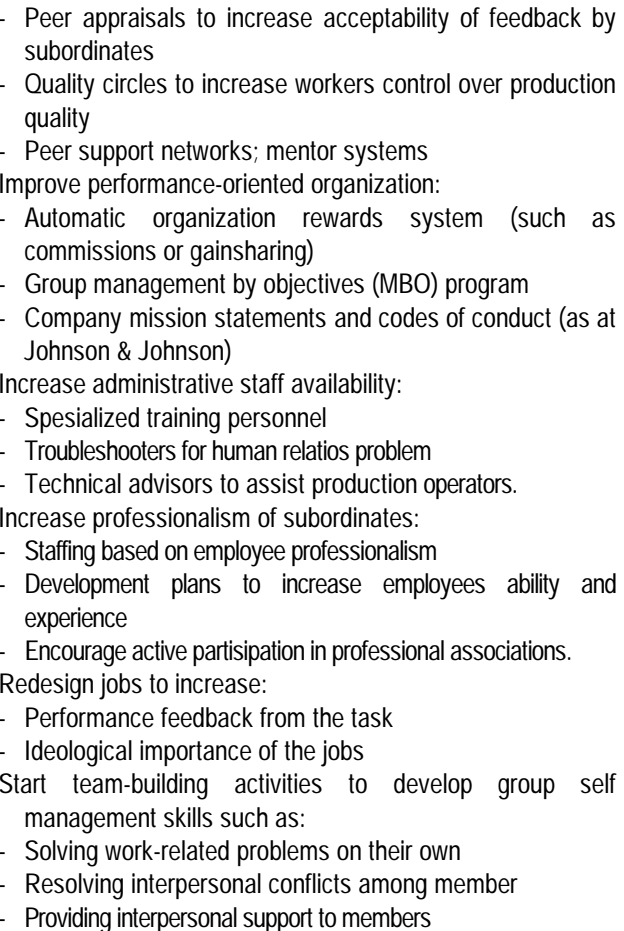 & $\begin{array}{l}\text { ence/expertise: } \\
\text { - } \quad \text { Provide visible champion of leader } \\
\text { - } \quad \text { Give leader important organizational responsibilities } \\
\text { - } \quad \text { Build leader's image through inhouse publications and other } \\
\text { means } \\
\text { Build organizational climate: } \\
\text { - } \quad \text { Reward small wins to increase subordinates confidence } \\
\text { - } \quad \text { Emphasize ceremony and myth to encourage cohesiveness } \\
\quad \text { and high performance norms } \\
\text { Incresae subordinates dependences on leader: } \\
\text { - } \quad \text { Create crises requiring immediate action } \\
\text { - Increase leader contrality in providing information } \\
\text { - } \quad \text { Eliminate one-over-one approvals } \\
\text { Increase leader's position power: } \\
\text { - } \quad \text { Change title to increase status } \\
\text { - Increase reward power } \\
\text { - } \quad \text { Eliminate resource base } \\
\text { Create cohesive work groups with high performance normas: } \\
\text { - } \quad \text { Provide physical setting conductive to teamwork } \\
\text { - } \quad \text { Encourage subordinates participation in group problem solving } \\
\text { - Increase groups status } \\
\text { - } \quad \text { Create intergroup competition }\end{array}$ \\
\hline
\end{tabular}

Sumber: Sofiati, Evi. (1995),"Mencari Pola Kepemimpinan yang Efektif", Usahawan, Januari, hal. 20-25.

\section{Model Diagnosis Perilaku Organisasi}

Organisasi adalah suatu kesatuan yang dinamis dan memiliki karakteristik sebagai sistem sosial yang terbuka. Perilaku organisasi ada pada setiap tingkat sistem (individu, kelompok, dan organisasi) dan merupakan proses yang tidak pernah berhenti. Kepemimpinan yang efektif akan terjadi jika seorang pemimpin mampu mendiagnosa perilaku anggota organisasi dalam sistem sosial yang kompleks. Agar dapat memahami perilaku organisasi, pemimpin organisasi membutuhkan suatu model diagnosa perilaku organisasi. Untuk keperluan tersebut, Nadler dan Tushman dalam Kolb, et al. (1998) menyodorkan sebuah model yang diberi nama "A Congruence Model for Diagnosing Organizational Behavior". Untuk memahami apa dan bagaimana model tersebut, terlebih dahulu kita perlu melihat organisasi sebagai suatu sistem terbuka yang memiliki komponen input, proses transformasi, dan output. Ada tiga kelompok input dalam sistem tersebut, yaitu: lingkungan, sumber daya, dan strategi. Proses tranformasi dapat dipandang sebagai interaksi antara empat komponen utama sistem organisasi, yang meliputi: tugas organisasi, individu yang ada dalam sistem organisasi, susunan organisasi, dan organisasi informal. Sedangkan output 
sistem merupakan hasil interaksi antar komponen input. Output utama dari sistem organisasi dapat berupa pengaruh individu dan perilaku serta fungsi sistem dalam pencapaian tujuan maupun adaptasi (lihat gambar 1).

\section{Gambar 1.}

A Congruence Model for Diagnosing Organizational Behavior

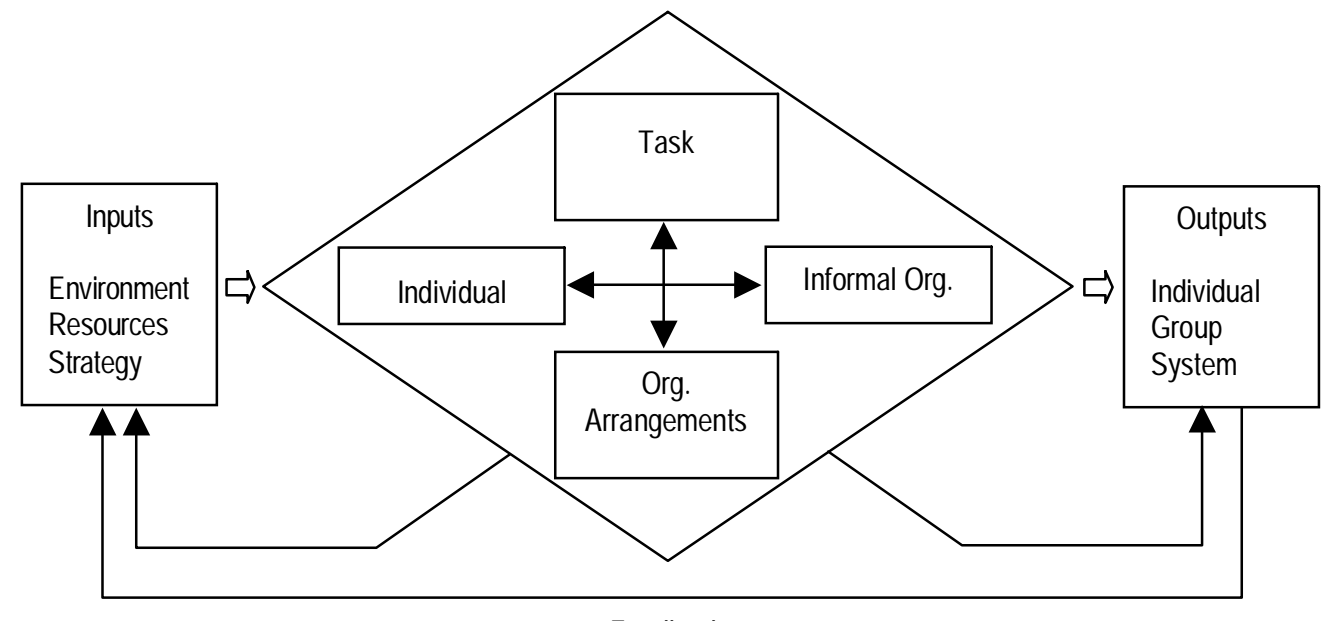

Feedback

Model diagnosa perilaku organisasi yang dimaksud di sini memfokuskan pada ketergantungan antar komponen dalam sistem organisasi. Organisasi dibentuk dari komponen atau bagian yang saling berinteaksi, dalam kondisi yang relatif seimbang, konsisten, dan saling menyesuaikan diri dengan komponen lainnya. Model ini bisa menjadi kerangka kerja yang memberi petunjuk dalam mendiagnosa, megevaluasi tindakan alternatif, dan memberikan umpan balik bagi hasil tindakan pemimpin. Gambar 2 menyajikan siklus pemecahan masalah dalam sistem organisasi. Siklus pemecahan masalah meliputi tiga tahapan, meliputi: 1) tahapan diagnosa (identifikasi sistem, menentukan sifat variabel kunci, diagnosa tingkat kesesuaian dan hubungan dengan perilaku, dan identifikasi problem kritis sistem organisasi), 2) tahapan penentuan solusi alternatif dan rencana tindakan (mengembangkan solusi alternatif, mengevaluasi strategi alternatif, dan memilih strategi yang akan dimplementasikan), 3) tahapan evaluasi dan umpan balik.

Gambar 2. Basic Phases of Using the Diagnostic Model 


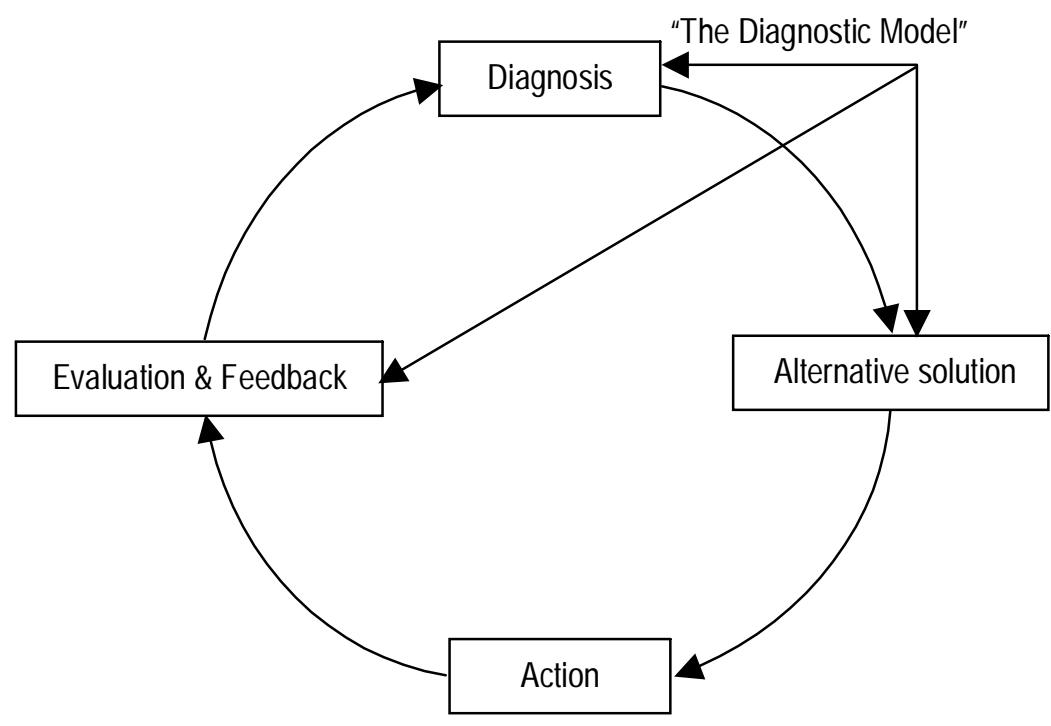

\section{PENUTUP}

Organisasi masa depan yang mampu bertahan adalah organisasi yang memiliki kepemimpinan yang efektif. Pemimpin yang efektif memiliki 10 karakteristik: 1) mengembangkan, melatih, dan mengayomi bawahan, 2) berkomunikasi secara efektif dengan bawahan, 3) memberi informasi kepada bawahan mengenai apa yang diharapkan perusahaan dari mereka, 4) menetapkan standar hasil kerja yang tinggi, 5) mengenali bawahan beserta kemampuannya, 6) memberi peranan kepada para bawahan dalam proses pengambilan keputusan, 7) selalu memberi informasi kepada bawahan mengenai kondisi perusahaan, 8) waspada terhadap kondisi moral perusahaan dan selalu berusaha untuk meningkatkannya, 9) bersedia melakukan perubahan dalam melakukan sesuatu, dan 10) menghargai prestasi bawahan.

Oleh karena menjadi pemimpin yang efektif membutuhkan proses, maka sebuah organisasi dapat menggunakan strategi berikut untuk meningkatkan keefektifan, yaitu: leadership substitues, ledaership enhancers, dan leadership neutralizers. Kepemimpinan yang efektif juga memerlukan model untuk mendiagnosa perilaku organisasi. Model yang bisa digunakan adalah "A Congruence Model for Diagnosing Organizational Behavior". Dengan model tersebut segala permasalahan perilaku organisasi dapat diketahui dan ditemukan strategi pemecahannya. 


\section{DAFTAR PUSTAKA}

Bass, Bernard M. (1985),"Leadership: Good, better, best". Organizational Dynamics, Vol.13, pp. 59-80.

Bass, Bernard M. (1990),"From Transactional to Transformational Leadership: Learning to Share the Vision", Organizational Dynamics, Vol.18, pp. 19-31.

Bass, Bernard M. and Avolio, Bruce, J. (1993)," Transformational Leadership and Organizational Culture". PAQ, Spring.

Brill, Peter L. and Worth, Richard. (1997),"The Four Levels of Corporate Change", Amacom: New York.

Chandra, Aditiawan. (1996),'Visionary Leadership: Gaya Kepemimpinan untuk Organisasi Masa Depan". Usahawan, September, hal. 10-14.

Collin, J.C. and Porras, J.I. (1996),"Buliding Your Company's Vision", Harvard Business Review, Sept-Oct.

Fiedler, Fred E., (1964),'The Contingency Model of Leadership Effectiveness". Advance in Experimental Social Psychology, Vol.3, No.4.

Handy, Charles. (1996),"The New Languange of Organizing and Its Implications for Leaders", Dalam Frances Haesselbein, Marshal Goldsmith, Richard Beckard (Eds). The Leader of The Future: New Vision, Strategies and Practices for The Next Era. San Fransisco: JosseyBass Publisher.

Heifetz, R.A. and Laurie, D.L. (1997)," The Work of Leadership", Harvard Business Review, Jan-Feb.

Hitt, William D. (1993),'The Model Leader: A Fully Functioning Person", Leadership \& Development Journal, Vol.14, No.7, pp. 4-11.

House, Robert J. (1971),"A Path-Goal Theory of Leader Effectiveness". Administrative Science Quarterly, September, p.321-338.

Kotter, John P. (1996)," Leading Change", Harvard University Business School. Mulyadi. (1998),"Total Quality Management", Yogyakarta: Aditya Media (Edisi I).

Nadler, David A. and Tushman, Michael.,"A Congruence Model for Diagnosing Organizational Behavior", dalam Kolb, David A., et al. (1998) The Organizational Behavior Readers. Sixth Ed., Prentice Hall: International Edition. 
Nanus, Burt. (1992), "Visionary Leadership". San Fransisco: Jossey-Bass Publishers.

Pradiansyah, Arvan. (1996), "Visionary Leader". Usahawan, September, hal. 1820.

Robbin, Stephen P. (1996),"Orgaizational Culture and Leadership". New Jersey: Prentice-Hall.

Seltzer, Joseph. and Bass, Bernard M. (1990),'Transformational Leadership: Beyond Initiation and Consideration", Journal of Management, Vol.16, No.4, pp. 693-703.

Sofiati, Evi. (1995),"Mencari Pola Kepemimpinan yang Efektif', Usahawan, Januari, hal. 20-25.

Spencer, Lyle M. and Spencer, Signe M. (1993),"Competence at Work: Models for Superior Performance", John Wiley \& son, Inc.

Spencer, Lyle M., McClelland, David C., Spencer, Signe M. (1994)," Competency Assesment Methods": History and State of the Art. Hay/McBer Research Press.

Tanri Abeng. (1997),"Dari Meja Tanri Abeng: Gagasan, Wawasan, Terapan, dan Renungan", Jakarta: Pustaka Sinar Harapan.

White, Randall P., Hodgson, Philip. and Crainer, Stuart. (1996),"The Future of Leadership: A White Water Revolution", London: Pitman Publishing. 